\title{
\#11
}

\section{Idealisme Wartawan dalam \\ Pusaran Bisnis Media: Runtuhnya Dinding Api}

\author{
Mia Dwianna Widyaningtyas
}

Duapuluh lima tahun lalu, saat saya menjadi wartawan, saya tidak pernah dipusingkan dengan urusan "idealisme". Hal ini karena dalam setiap tugas liputan, dalam benak saya hanya ada satu tujuan yakni selalu ingin membuat berita yang baik, yang memenuhi unsur nilai berita dan tentu saja eksklusif. Hingga saya keluar dari profesi wartawan, saya tidak pernah tahu dan tidak pernah bersinggungan dengan urusan bisnis media tempat dimana saya bekerja. Kondisi ini dimungkinkan karena pada masa itu kami, para wartawan, tidak pernah terlibat dengan urusan iklan dan memang tidak perlu tahu pendapatan media. Kala itu, ada sebuah garis batas yang dalam jurnalisme dikenal dengan istilah dinding api (firewall). Pada masa suratkabar masih merajai dunia media, dinding api yang 
membatasi bagian redaksi dan bagian iklan tersebut "cukup tinggi dan cukup tebal", sehingga para wartawan tidak pernah tahu aktivitas bagian iklan.

Dinding api (firewall) dalam jurnalistik merupakan sebuah istilah atau ungkapan untuk menggambarkan pagar pembatas antara ruang redaksi dan bagian iklan (Harsono, 2010). Pemisahan yang dimaksud di sini adalah pemisahan antara berita dan iklan dalam penyajian di media. Firewall atau dinding api ini menjaga kemerdekaan newsroom dari bujukan pemasang iklan atau kekuasaan apa pun. Ketika bisnis media tidak semasif dan tidak seketat sekarang, dinding api menjadi sebuah ikhtiar media untuk menjaga profesionalismenya. Pertanyaannya kemudian adalah, apakah konsep dinding api ini masih dipergunakan pada era media digital ini? Hal inilah yang menjadi ketertarikan penulis untuk membahas idealisme wartawan dan keberadaan dinding api dalam bisnis media digital.

\section{Model Bisnis Media di Era Digital, dan Keruntuhan Dinding Api (Firewall)}

Era digital saat ini memunculkan kondisi jurnalisme yang berbeda dengan dua puluh lima tahun lalu. Kondisi jurnalisme yang ada sekarang dengan kebebasan yang relatif lebih besar menimbulkan dominasi kepentingan bisnis media yang juga lebih besar. Di era digital ini juga terjadi fenomena global peralihan media cetak ke platform digital karena mengikuti tren perubahan pola konsumsi pembaca. Nielsen pada Agustus 2020 sebagaimana Katadata.co.id (Ekarina, 2020) mengungkapkan mengenai adanya perubahan pola pembaca Indonesia dalam mengakses media. Menurut Nielsen dalam Katadata.co.id (Ekarina, 2020), jumlah pembaca media online dalam waktu tersebut mencapai hingga 6 juta orang, sedangkan pembaca media cetak sebanyak 4,5 juta orang. Digitalisasi telah melahirkan banyak media dalam jaringan (online). Menurut data Dewan Pers, jumlah media online sekitar 43.000, 
meski jumlah media yang terdaftar secara resmi jauh di bawah jumlah tersebut.

Realitas yang terjadi selanjutnya adalah perubahan ekonomi produksi berita dalam konteks di mana "banyak yang masih menyukai gagasan jurnalisme" tetapi "tidak banyak yang mau membayarnya"(Wahl-Jorgensen \& Hanitzsch, 2009). Sementara industri media digital mendapat tantangan dimana pendapatan iklan tidak sebesar media cetak, terlebih dengan adanya persaingan dengan perusahaan teknologi global; tantangan untuk mendapatkan iklan semakin sulit. Menurut data E-Marketer di tahun 2020, total belanja iklan digital di Indonesia adalah sebesar 658,5 juta dollar AS atau sekitar Rp 9,5 triliun dengan proyeksi pertumbuhan dalam lima tahun ke depan berada pada angka rerata 12,2 persen setiap tahunnya. Pertumbuhan tersebut didapat dari beberapa format iklan digital utama yaitu display ad, search ad, dan classified ad (Ekarina, 2020).

Rasmus Kleis Nielsen (Wahl-jorgensen \& Hanitzsch, 2020) mencatat era digital telah menimbulkan perhatian besar terhadap beberapa aspek yakni: (1) pilihan dan persaingan yang meningkat pesat, (2) kebangkitan perusahaan platform yang memenangkan banyak perhatian audiens dan anggaran pengiklan, dan (3) transformasi dalam cara organisasi berita menghasilkan uang karena pendapatan iklan menyusut dan semakin banyak organisasi berita berfokus pada model pembayaran dan pada berbagai sumber pendapatan tambahan seperti konten bersponsor, ecommerce, dan acara langsung. Kini tantangan yang dihadapi industri media digital adalah pemasukan dari iklan yang umumnya tak sebesar media cetak. Kompetisi mendapatkan ceruk iklan lebih sulit karena bersaing dengan perusahaan teknologi global, seperti Facebook, Youtube, atau Tiktok. 
Bisnis media sendiri merupakan bisnis informasi. Bisnis berita hanya bagian kecil dari industri media dan hiburan, sehingga digitalisasi memberi pengaruh sangat besar terhadap bisnis media. Teknologi berpengaruh terhadap penyajian berita melalui pengaruhnya terhadap intensitas persaingan ekonomi dan norma produksi berita (Kavanagh et al., 2019). Saat ini, perusahaan media bukan hanya bersaing dengan sesama perusahaan media. Perusahaan non media pun kini masuk dalam daftar sebagai pesaing perusahaan media. Meski bukan merupakan bagian dari industri media, mereka berjualan informasi dan laku keras. Kondisi ini pada akhirnya membuat semua perusahaan ini bersaing untuk mendapatkan perhatian pengguna media. Sebagian besar dari perusahaan ini bersaing untuk mendapatkan uang dari pengguna media dan mendapatkan iklan. Warga negara atau konsumen akan menjadi raja: akses ke berita dan segala jenis urusan terkini akan tersedia untuk semua, kapan pun, di mana pun (Kavanagh et al., 2019). Sementara pengguna media harus mengalokasikan waktu di antara berbagai pilihan media yang terus berkembang. Era digital yang berkembang demikian cepat, berimplikasi pada pergualan antara idealisme dan bisnis. Bisnis media yang tergantung pada pendapatan iklan harus mengubah strategi agar para pengiklan mau tetap menyokong bisnis media.

Teknologi baru telah memicu perkembangan bentuk-bentuk produksi dan kreasi berita yang secara fundamental baru dan telah menyebabkan perubahan dalam penyajian berita (Kavanagh et al., 2019). Dutton (2009) berpendapat bahwa media sosial dan internet memungkinkan bentuk produksi berita kolaboratif yang mengandalkan jaringan individu dan saluran informal daripada saluran formal. Sementara DVorkin (2016) menggambarkan jurnalisme kolaboratif baru yang beroperasi di seluruh organisasi berita dan di tingkat lokal, individu menciptakan jurnalisme "open source ". Aspek lain dari pendekatan yang berfokus pada teknologi adalah bagaimana kecepatan siklus berita dan dinamika politik yang menyeluruh dapat mempengaruhi penyajian berita. Di 
Indonesia, teknologi digital telah menciptakan model bisnis baru untuk sebagian besar media arus utama. Tapsell (2013) mendefinisikan model ini sebagai konglomerat digital. Model bisnis ini, oleh para eksekutif media digital dideskripsikan sebagai sebuah ekosistem yang mencakup beberapa jenis bisnis yang mencakup game, tiket, acara, e-commerce, dan banyak lagi. Istilah "ekosistem" adalah istilah umum dikatakan oleh kepala pemberitaan di Indonesia dan digunakan secara luas untuk menggambarkan hubungan yang berkembang antara perusahaan media dan usaha patungan bisnis digital lainnya.

Efek dari digitalisasi dan perubahan cara media menyajikan berita adalah hilangnya batas antara berita, opini, fiksi dan iklan (advertorial). Batas yang dalam paradigma jurnalisme lama dikenal dengan istilah pagar api (firewall) menjadi pembeda agar pembaca tidak merasa terkecoh atau dirugikan. Pagar api yang dulu menjadi bagian dari tanggungjawab media, kini tidak lagi menjadi suatu hal yang wajib dipatuhi(Gemiano, 2021). Media berusaha bertahan di era digital ini dengan menomorsatukan bisnis dan mengabaikan prinsip-prinsip dasar jurnalisme. Bila dulu pengelola media membedakan produk atau konten ke dalam rubrik-rubrik, kini pembaca sulit membedakan konten, karena pagar api yang dulu jelas terlihat, kini melebur dalam satu format penyajian media.

\section{Idealisme Wartawan dalam Bisnis Media Digital}

Pada awal munculnya pers di Indonesia, para pejuang pers selalu menggaungkan tiga pilar: idealisme, profesionalisme, dan komersialisme dalam setiap aktivitas. Idealisme adalah cita-cita, obsesi, sesuatu yang harus dikejar, dijangkau dengan segala daya dan cara yang dibenarkan menurut etika, yang diimplementasikan dalam fungsi media informasi, pendidikan, huburan dan kontrol sosial (Sumadiria, 2005). Hal ini terus menerus diupayakan kendati dengan terseok-seok. Kini, upaya untuk menegakkan idealisme 
terkendala oleh kebutuhan pasar. Pesatnya perkembangan teknologi mulai mengubah manajemen media.

Perubahan model bisnis media pada era digital, secara langsung berimplikasi pada kerja para wartawan. Media kini tergoda menyediakan informasi yang "ingin" dibaca, bukan lagi apa yang "seharusnya" dikonsumsi publik sebagai sebuah produk jurnalisme, sehingga menyajikan berita tanpa rasa jurnalisme. Akibatnya wartawan bekerja dengan mengikuti pola kerja model baru media. Media online yang menuntut kecepatan, membuat wartawan dibebani dengan target berita secara kuantitatif. Saya pernah berbincang dengan salah satu pengelola media online. Menurut dia, pada media online yang dikelolanya, wartawan diberi target untuk dapat menghasilkan sekitar 10 berita per hari. Pola kerja seperti ini menyebabkan potensi hilangnya satu atau lebih prinsip jurnalisme. Teknologi digital secara langsung membebaskan wartawan dari sebuah proses produksi yang kompleks, yang membuat wartawan dapat langsung memproduksi dan mengontrol editorial materi mereka. Namun tuntutan untuk menyajikan berita 24 jam non-stop, menyebabkan banyak wartawan mengeluh bahwa mereka harus mengambil jalan pintas untuk menghasilkan materi untuk banyak media (Rudin \& Ibbotson, 2002). Situasi seperti ini memunculkan berita dengan kualitas yang dangkal.

Tuntutan memproduksi berita dengan target kuantitatif mengakibatkan para wartawan semakin terikat dengan meja berita atau studio, sehingga tidak dapat keluar dan mencari tahu berita 'sebenarnya'. Hal yang lebih berbahaya dari situasi ini adalah semakin banyak jurnalis yang hanya menerima pernyataan dan informasi resmi dari pemerintah atau siapa pun yang mengeluarkan informasi, tanpa mempertanyakan atau menyelidiki lagi hal yang sebenarnya terjadi karena waktu yang terbatas. Wartawan menjadi layaknya sebuah mesin yang memproduksi berita. Idealisme yang menjadi ruh dari sebuah produk jurnalisme sedikit demi sedikit 
hilang karena tuntutan dari pihak perusahaan dan pola kerja media seperti ini.

Hal ini akan semakin parah dengan tuntutan perusahaan agar konten dapat menarik sebanyak-banyaknya pembaca atau sebanyak-banyaknya klik. Godaan untuk membuat berita yang punya "nilai klik" tinggi ini membuat wartawan dan media kerap tergelincir pada tindakan yang cenderung melanggar etika. Sebagai contoh beberapa media online kerap menyajikan berita dalam ranah privat selebriti, semisal kehidupan ranjang para artis, atau konflik rumah tangga para artis; sehingga isi berita pun hanya dibuat untuk memenuhi keinginan pasar. Idealisme wartawan yang seharusnya menjadi dasar dari sebuah aktivitas jurnalistik juga mulai menghilang karena iklim adu cepat dalam persaingan media online.

Iklim adu cepat yang terjadi pada industri media secara tidak langsung membawa dampak yang tak diinginkan, yakni mengorbankan salah satu prinsip dalam jurnalisme, yaitu akurasi. Akurat dalam hal ini ketepatan dan kebenaran sebuah berita. Kebutuhan untuk menyajikan berita secepat mungkin menjadikan sebuah peristiwa yang tayang di media sering kali mengabaikan akurasi. Wartawan tidak lagi memiliki waktu yang cukup untuk memastikan kesolidan fakta, kejelasan tulisan (tidak dipersepsi berbeda oleh pembaca) dan keakuratan kutipan (Filak, 2019). Konsekuensi dari ketidakakuratn ini adalah turunnya kredibilitas media, sebagaimana diungkapkan oleh Filak (2019) bahwa tidak peduli seberapa cepat Anda menyampaikan informasi kepada seseorang atau betapa luar biasa visual Anda yang menakjubkan, jika pekerjaan Anda kurang akurat, tidak ada hal lain yang penting. Harapan pertama dan utama khalayak terhadap wartawan adalah wartawan mengedepankan informasi yang benar secara faktual 


\section{Kolaborasi Media, Wartawan, dan Khalayak}

Idealisme wartawan memang sudah mulai tergerus bisnis media, namun demikian masih ada media-media yang tetap berusaha mempertahankan idealisme dengan sisa-sisa energi, Biaya industri pers sangat besar sementara persaingan untuk mendaptkan kue iklan semakin ketat seiring banyaknya perusahaan pers yang bermunculan. Pers dihadapkan pada pilihan mengikuti arus atau tenggelam dalam dalam idealisme. Idealisme wartawan di era digitalisasi dan bisnis media ini memang benar-benar diuji, perlu daya tahan yang kuat agar tidak runtuh atau bahkan mati. Pers harus bergerak agar dapat bertahan di era digital. Tempo, Kompas, atau The Jakarta Post misalnya. Ketiga media tersebut saat ini masih menyajikan berita-berita dengan standar jurnalisme yang memadai. Pergulatan idealisme dan bisnis untuk tumbuh bersama dapat disiasati dengan kelenturan dalam pemberitaan. Bagaimanapun, idealisme dan bisnis harus berjalan seiring, karena cita-cita dalam idealisme pers hanya dapat berjalan kalau perusahaan pers untung. Teknologi baru telah memungkinkan siapa pun yang memiliki komputer dapat menyebarkan informasi seluas organisasi berita terbesar. Namun situs Internet yang dirancang dengan baik, tidak peduli seberapa baik itu ditulis atau seberapa sering diperbarui; belum tentu menjadi sumber berita yang andal. Kenyataannya, dalam dunia yang kompleks ketika informasi bukan lagi komoditas langka, peran jurnalis menjadi lebih penting dari sebelumnya (Detrani, 2011). Jurnalisme memerlukan kecerdasan yang lebih tinggi. Pada era digital jurnalis dituntut berkemampuan majemuk untuk multimedia dan multitasking. Oleh karena itu, jurnalis harus terus menerus belajar, untuk meningkatkan pengetahuannya, memperdalam pemahamannya mengenai kode etik dan kode prilaku dan mengasah keterampilannya, meskipun orientasi bisnis media telah berubah.

Industri media saat ini dihadapkan pada tiga hal: pertama apa yang akan diperhatikan orang, apa yang mungkin dibayar oleh publik, dan 
ketiga apa yang akan dibayar pengiklan (Wahl-jorgensen \& Hanitzsch, 2020). Tiga hal ini menunjukkan perlunya strategi baru dalam mengelola bisnis media. Strategi yang dapat menghasilkan produk jurnalisme yang baik dan juga menghasilkan keuntungan. Beberapa cara yang sudah dikenal untuk mendanai industri media adalah menggantungkan pada berlangganan (untuk mediacetak berplatform digital) dan model bisnis berbasis iklan (Lugmayr \& Zotto, 2016). Meskipun kedua cara ini sama-sama memperoleh pendapatan dari pelanggan dan pengiklan, keduanya memiliki format yang sedikit berbeda dengan media cetak tradisional. Dalam format berlangganan, ada dua teknis yang ditawarkan, bisa dengan berlangganan suratkabar/majalah digital atau berlangganan konten media online secara premium. Di Indonesia, beberapa perusahaan yang telah mengaplikasikan format ini antara lain: The Jakarta Post, Kompas.id, dan Tempo (majalah dan Koran). Tempo misalnya, menawarkan konsep independensi dan kualitas isi yang diusungkan kepada pengunjung situs Tempo.co.id. Konsep seperti ini diasumsikan dapat membuat Tempo independen dan bebas menjalankan idealismenya. Sedangkan format pembiayaan berbasis iklan adalah penyajian iklan di media online dengan konten yang relevan dengan preferensi pembacanya. Algoritma pembaca media membuat penyajian iklan menjadi hal yang personal dan native. Bisnis model ini memberikan konten secara cuma-cuma kepada khalayak. Agar dapat mencapai target keuntungan yang besar, media memerlukan trafik yang besar. Oleh karena itu pengelola media mengaplikasikan model pemberitaan clickbait.

Selain dua model bisnis media seperti ini, saat ini sejumlah media mulai menggunakan model pendapatan baru adalah crowdfunding (Aitamurto, 2011), dengan konsep open donation (pendanaan terbuka) kepada siapa pun untuk menyumbang dalam rangka membiayai tulisan yang diterbitkan di media online. Crowdfunding semakin banyak digunakan untuk mendanai jurnalisme di beberapa platform online. Pengguna media dapat memberikan donasi sesuka 
mereka, karena pada dasarnya konten yang dibagikan dapat diakses secara gratis. Dengan konsep ini orang akan membayar karena puas dengan isi media yang dihasilkan. Media yang menerapkan bisnis model ini biasanya adalah media yang spesifik, dengan jumlah pembaca kecil tetapi potensial menghasilkan keuntungan. Model bisnis konsep ini dapat menjadi alternatif bagi media untuk menjaga marwah idealisme dengan tetap menjalankan fungsi lembaga ekonomi. Khalayak sebagai pengguna akhir merasa diberdayakan dan didorong untuk berpartisipasi dalam produksi dan distribusi jurnalisme (Aitamurto, 2011), sehingga menjadi mitra dalam mengisi content media.

\section{Kesimpulan}

Bisnis media merupakan bisnis informasi yang tetap harus memegang prinsip-prinsip jurnalisme dalam aktifitasnya. Komersialisme (bisnis) dan idealisme merupakan dua pilar yang tidak dipisahkan. Kedua pilar jurnalisme in harus berjalan beriringan untuk dapat membuat industri media hidup dengan baik. Oleh karena itu model bisnis yang mengolaborasikan media, wartawan, dan khalayak dapat menjadi alternatif mewujudkan media yang sehat dengan tetap mengedepankan prinsip-prinsip jurnalisme.

\section{Referensi}

Aitamurto, T. (2011). The impact of crowdfunding on journalism: Case study of spot.us, a platform for community-funded reporting. Journalism Practice, 5(4), 429-445. https://doi.org/10.1080/17512786.2010.551018

Detrani, J. R. (2011). Journalism Theory and Practice. Apple Academic Press.

Dutton, W. H. (2009). Prometheus: Critical Studies in Innovation The Fifth Estate Emerging through the Network of Networks. August 2014, 37-41. https://doi.org/10.1080/08109020802657453

DVorkin, L. (2016). Inside Forbes: The State of Digital News, Or 25 Web Sites Captured in 3 Revealing Charts. Forbes. https://www.forbes.com/sites/lewisdvorkin/2016/01/26/inside-forbes- 
the-state-of-digital-news-or-25-web-sites-captured-in-3-revealing-charts/

Ekarina. (2020). Transformasi Bisnis Media di Era Digital Terus Bergulir. Katadata. https://katadata.co.id/ekarina/brand/5fcfc332efab0/transformasi-

bisnis-media-di-era-digital-terus-bergulir diakses 2 April 2021 pukul 20:03 WIB

Filak, V. F. (2019). Dynamics of Media Writing. Sage Publications. https://doi.org/10.1017/CB09781107415324.004

Gemiano, D. (2021, Maret 24). Membayangkan Masa Depan Media Digital Indonesia...

https://money.kompas.com/read/2021/03/24/175633326/membayang kan-masa-depan-media-digital-indonesia?page=all

Harsono, A. (2010). Agama saya adalah jurnalisme. Penerbit Kanisius.

Kavanagh, J., Marcellino, I. W., Blake, J. S., Smith, I. S., Davenport, S., \& Tebeka, I. M. G. (2019). News in Digital Age: Comparing the Presentation of News Information over Time and Across Media Platform. Rand Corporation.

Lugmayr, A., \& Zotto, C. D. (2016). Media Business and Innovation. Springer Heidelberg.

Rudin, R., \& Ibbotson, T. (2002). An Introduction to Journalism:Essential. Techniques and Background Knowledge. 45.

Sumadiria, A. S. H. (2005). Jurnalistik Indonesia: menulis berita dan feature: panduan praktis jurnalis professional. Simbiosa Rekatama Media.

Tapsell, R. (2013). Media Power in Indonesia: Oligarchs, Citizens And The Digital Revolution. In Rowman \& Littlefield International (Vol. 53, Nomor 9). https://doi.org/10.1017/CB09781107415324.004

Wahl-jorgensen, K., \& Hanitzsch, T. (2020). THE HANDBOOK OF JOURNALISM STUDIES, 2ND EDITION Edited. Routledge. https://lccn.loc.gov/2019008919

Wahl-Jorgensen, K., \& Hanitzsch, T. (2009). The handbook of journalism studies. Routledge.

\section{Sumber Internet}

https://dewanpers.or.id/publikasi/opini_detail/147/Publik_Perlu_Media_Terverif ikasi diakses 30 Maret 2021 pukul 19:45 WIB 
www.forbes.com/sites/lewisdvorkin/2016/01/26/inside-forbes-the-state-of-

digital-news-or-25-web-sites-captured-in-3-revealing-charts/ , diakses 2 April 2021 pukul 20:03 WIB

https://dewanpers.or.id/publikasi/opini_detail/74/Jurnalisme_Partisan diakses 2 April 2021 pukul 20:15 WIB

\section{Profil Penulis}

Mia Dwianna Widyaningtyas. Biasa dipanggil Mia, merupakan dosen pada program studi Ilmu Komunikasi FISIP Universitas Sultan Ageng Tirtayasa Serang Banten. Menyelesaikan pendidikan dasar hingga tinggi di Bandung. Tertarik pada penelitian dengan tema perempuan, media, dan jurnalistik. Beberapa penelitian yang telah dihasilkan antara lain: Pola Komunikasi Pemerintah Provinsi DKI Jakarta mengenai kasus covid-19 (Analisis isi pola dan bentuk pesan di website https://corona.jakarta.go.id/id periode Maret - Juni 2020). Pengalaman Komunikasi Perempuan dengan Baby Blues Syndrom dalam Paradigma Naratif (2018), Optimalisasi Media Sosial oleh Komunitas Penggerak Halal dalam menyosialisasikan Gaya Hidup Halal Kepada Masyarakat, Aktivitas Kader Perempuan dalam Komunikasi Politik (2015). Email: mia.dwiana@untirta.ac.id 